\title{
Electronic monitoring of chemical DNA denaturation on nanocrystalline diamond electrodes with different molarities and flow rates
}

\author{
M. S. Murib ${ }^{*, 1}$, B. van Grinsven ${ }^{1}$, L. Grieten ${ }^{1}$, S. D. Janssens ${ }^{1}$, V. Vermeeren ${ }^{2}$, K. Eersels ${ }^{1}$, J. Broeders', \\ M. Ameloot ${ }^{2}$, L. Michiels ${ }^{2}$, W. De Ceuninck ${ }^{1,3}, K$. Haenen ${ }^{1,3}$, M. J. Schöning ${ }^{4}$, and P. Wagner ${ }^{1,3}$ \\ ${ }^{1}$ Institute for Materials Research, Hasselt University, Wetenschapspark 1, 3590 Diepenbeek, Belgium \\ ${ }^{2}$ Biomedical Research Institute, Agoralaan, Hasselt University, 3590 Diepenbeek, Belgium \\ ${ }^{3}$ IMEC vzw, Division IMOMEC, Wetenschapspark 1, 3590 Diepenbeek, Belgium \\ ${ }^{4}$ Institute for Nano- and Biotechnologies, Aachen University of Applied Sciences, Heinrich-Mußmann-Straße 1, \\ 52428 Jülich, Germany
}

Received 9 November 2012, revised 5 March 2013, accepted 23 March 2013

Published online 6 May 2013

Keywords CVD diamond, denaturation time constant, deoxyribonucleic acid, electrochemical impedance spectroscopy, mutation analysis

* Corresponding author: e-mail mohammed.murib@uhasselt.be, Phone: +32 (011) 26 8817, Fax: +32 (011) 47031334

Probe DNA, consisting of a 36-mer fragment was covalently immobilized on nanocrystalline chemical vapour deposition (CVD) diamond electrodes and hybridized with a 29-mer target DNA. In this paper, we report on the label-free real-time electronic monitoring of DNA denaturation upon exposure to $\mathrm{NaOH}$ at different flow rates and molarities, using electrochemical impedance spectroscopy as readout technology. The impedance response was separated into a denaturation time constant and a medium exchange time constant by means of a double exponential fit. It was observed that the denaturation time is dependent on the flow rate as well as on the molarity of the $\mathrm{NaOH}$. Surprisingly, it was observed that at low molarities $(0.05 \mathrm{M})$ the DNA does not fully denature at low flow rates. Only after flushing the flow cell a second time with $0.05 \mathrm{M}$ $\mathrm{NaOH}$, complete denaturation was achieved. Confocal images were obtained and plotted in $3 \mathrm{D}$ graphs to confirm the results. This paper provides a systematic overview of measured denaturation times for different flow rates and at different molarities of $\mathrm{NaOH}$. Optimization of these parameters can be a valuable asset in the field of mutation analysis.
1 Introduction Diamond has proven to be an excellent platform for biomedical research due to its outstanding material properties such as chemical inertness, thermal conductivity and electronic properties [1]. In addition, intrinsic diamond displays a high chemical and electrochemical stability and has a wide band gap $(5.5 \mathrm{eV})$ [2-4]. Diamond is an insulator and can be made semiconductive by chemical doping [5]. In recent years there has been a major development of DNA electrochemical biosensors such as field-effect sensors [6-8] and sensors monitoring electrical surface properties such as conductance, resistance [9] and capacitance [10]. In addition, diamond proved to be a good transducer for protein sensing [11-13]. In previous work it was established that the monitoring of chemically induced denaturation at room temperature is an interesting approach to measure DNA duplex stability as an alternative to thermal denaturation at elevated temperatures $[14,15]$. Elaborating on these results we now report on the electronic monitoring of DNA denaturation by $\mathrm{NaOH}$, induced at different flow rates $\left(0.1-0.4 \mathrm{~mL} \mathrm{~min}^{-1}\right)$ with variable molarities $(0.05-$ $0.4 \mathrm{M}$ ), using electrochemical impedance spectroscopy as readout technology. The aim of this paper is to find optimal DNA denaturation conditions, ensuring complete denaturation within the shortest time span possible, while leaving the possibility for electrochemical detection. These optimal conditions can be implemented in single nucleotide polymorphism (SNP) detection studies based on electrochemical detection of DNA denaturation [14]. 


\section{Experimental}

2.1 Synthesis of nanocrystalline diamond (NCD) A 2-inch doped (1-2 $\Omega \mathrm{cm})$ p-type crystalline silicon wafer (100) was seeded with ultra-dispersed detonation diamond powder in an ultrasonic bath. NCD films with thicknesses of $\sim 100 \mathrm{~nm}$ and grain sizes of $50 \mathrm{~nm}$ were grown on this silicon substrate, using microwave plasma-enhanced chemical vapour deposition (MPECVD) in an ASTEX reactor equipped with a $2.45 \mathrm{GHz}$ microwave generator. This is achieved by using a standard mixture of $15 \mathrm{sccm}$ methane gas $\left(\mathrm{CH}_{4}\right)$ and $485 \mathrm{sccm}$ hydrogen gas $\left(\mathrm{H}_{2}\right)$ to deposit the NCD thin films onto the silicon wafer. The growth was performed under a pressure of $33 \mathrm{Torr}$, and temperature of $710^{\circ} \mathrm{C}$, the microwave power was set to $3500 \mathrm{~W}$. The growth rate was $\sim 600 \mathrm{~nm} \mathrm{~h}^{-1}$. In addition, the chemical vapour deposition (CVD) deposition was done with an admixture of trimethyl borane $\left(\mathrm{B}\left(\mathrm{CH}_{3}\right)_{3}\right)$ to the $\mathrm{CH}_{4}$ gas with a concentration ratio of $200 \mathrm{ppm} \mathrm{B/C}$ to dope the NCD with boron and achieve a good electrical conductivity in the range of $1 \Omega \mathrm{cm}[16]$.

2.2 Sample preparation Probe DNA, consisting of a 36-mer fragment was covalently immobilized on NCD electrodes and hybridized with 29-mer target DNA. First, the diamond surface was hydrogenated. The hydrogenation was done at $700{ }^{\circ} \mathrm{C}$ during $30 \mathrm{~s}$ at $3500 \mathrm{~W}, 12 \mathrm{kPa}$ and $1000 \mathrm{sccm}$ hydrogen gas $\left(\mathrm{H}_{2}\right)$ [17]. After hydrogenation the samples were placed inside a glovebox under nitrogen atmosphere. The hydrogenated NCD was covered with a thin film of unsaturated fatty acid (10-undecenoic acid) and was exposed to $\mathrm{UV}$ radiation $\left(254 \mathrm{~nm}, 265 \mathrm{~mW} \mathrm{~cm}^{-2}\right)$ for $20 \mathrm{~h}$ under nitrogen atmosphere. The double bonds of the unsaturated fatty acid chains were broken down and a covalent bond with the hydrogen-terminated diamond was established. This process was mediated by photoemission from the surface as proposed for the photochemical grafting of alkenes to silicon surfaces $[3,4]$. The fatty acid layer was about $2 \mathrm{~nm}$ thick [18]. The unbound fatty acid chains were washed off using acetic acid and ultrapure water at $120^{\circ} \mathrm{C}$. In this way, a carboxyl $(\mathrm{COOH})$ terminated NCD surface was obtained. Zero-length 1-ethyl-3-3-dimethylaminopropyl-carbodiimide (EDC) was used for the covalent coupling of the $5^{\prime}$ side of an aminomodified 36-mer ssDNA fragment to the carboxyl-terminated surface in 2-[N-morpholino]-ethannesulphonic acid (MES) buffer at $4{ }^{\circ} \mathrm{C}$. In a following step, $6 \mu \mathrm{L}$ FAM-488modified DNA was mixed with $14 \mu \mathrm{L} 1 \times$ PCR buffer and added to the ssDNA-modified NCD sample. The sample was then incubated at $35^{\circ} \mathrm{C}$ for $2 \mathrm{~h}$. Non-specifically bound DNA was removed using a double washing step. In a first step, the sample was washed with $2 \times$ saline sodium citrate (SSC) $+0.5 \%$ sodium dodecyl sulphate (SDS) for $30 \mathrm{~min}$. Secondly, the sample was washed twice with $0.2 \times$ SSC at $30{ }^{\circ} \mathrm{C}$ for $5 \mathrm{~min}$. Finally, the sample was rinsed with phosphate buffered saline (PBS) of $\mathrm{pH} 7.2$ and stored in PBS at $4{ }^{\circ} \mathrm{C}$ [2]. By using low salt concentrations in comparison to the concentration in the hybridization buffer and by washing at temperatures lower than hybridization temperature we avoided premature denaturation.
2.3 Experimental setup Electrochemical impedance measurements were performed using a homemade miniaturized impedance spectroscopy unit [19]. The impedance spectroscopy unit measures the impedance in a frequency range of $100 \mathrm{~Hz}$ to $100 \mathrm{kHz}$, built up logarithmically with 10 equidistant frequencies per decade and a scanning speed of $5.3 \mathrm{~s}$ per sweep. The amplitude of the AC voltage was fixed to $10 \mathrm{mV}$ with an offset of $0 \mathrm{mV}$ [19]. A transparent Perspex flow cell with an inner volume of $110 \mu \mathrm{L}$ was used to exchange media. In this cell, the DNA-modified NCD sample acts as a working electrode, and a gold wire (diameter $500 \mu \mathrm{m}$ ) acts as a counter electrode. The working electrode was pressed onto a copper lid using silver paste. The copper lid serves as back electrode as well as heat sink. Dilutions of PBS and $\mathrm{NaOH}$ buffer used in all experiments were made from $10 \times \mathrm{PBS} \mathrm{pH} 7.4$ and $2 \mathrm{M} \mathrm{NaOH}$ stock solutions in ultrapure water. The exchange of media was conducted through two identical programmable syringe pumps (ProSense, model NE-500, The Netherlands) enabling flow rates of $0.73 \mu \mathrm{Lh}^{-1}$ to $1699 \mathrm{~mL} \mathrm{~h}^{-1}$. All measurements were done at room temperature $\sim 19.2^{\circ} \mathrm{C}$. Conductivity measurements on the different solutions were performed using a conductivity meter (Mettler Toledo, Zaventem, Belgium).

2.4 Fluorescence imaging Fluorescence images were taken on a Zeiss LSM 510 META Axiovert $200 \mathrm{M}$ laser scanning confocal fluorescence microscope. To excite the FAM-488 fluorescence dye, a $488 \mathrm{~nm}$ argon-ion laser was used with a maximum intensity at the sample surface of $30 \mu \mathrm{W}$, in order to avoid bleaching during the image acquisition. The peak emission has a longer wavelength of $518 \mathrm{~nm}$ due to vibrational relaxation of the FAM molecule after photon absorption. All images were collected with a $10 \times / 0.3$ Plan Neofluar air objective with a working distance of $5.6 \mathrm{~mm}$. The image size was 225 by $225 \mu \mathrm{m}^{2}$. The pinhole size was $150 \mu \mathrm{m}$ and the laser intensity was set at $10 \%$. The detector gain, being a measure for the photomultiplier voltage in arbitrary units, was set to 950 . The fluorescent intensity was analysed using ImageJ software.

\section{Experimental results}

3.1 Impedimetric characterization Figure 1 shows the Nyquist plots for a DNA-modified diamond sample in different states in PBS buffer solution. The NCD was modified first with ssDNA and measured with the impedance spectroscopy unit. The real $\left(Y_{\text {real }}\right)$ and imaginary $\left(Y_{\text {imaginary }}\right)$ admittance were found to be 0.00249 and $0.0012 \Omega^{-1}$, respectively. After hybridization with target DNA the impedance was measured again, resulting in 0.00242 and $0.00121 \Omega^{-1}$ for $Y_{\text {real }}$ and $Y_{\text {imaginary. Then, the DNA was }}$ denatured by introducing $0.1 \mathrm{M} \mathrm{NaOH}$ into the flow cell and a third Nyquist plot is constructed. As a result, $Y_{\text {real }}$ increased to $0.00256 \Omega^{-1}$ and $Y_{\text {imaginary }}$ decreased to $0.0011 \Omega^{-1}$. After denaturation the impedance was not completely reversed towards its initial state. The lack of this complete reversibility is yet unclear but might be due to the induced 


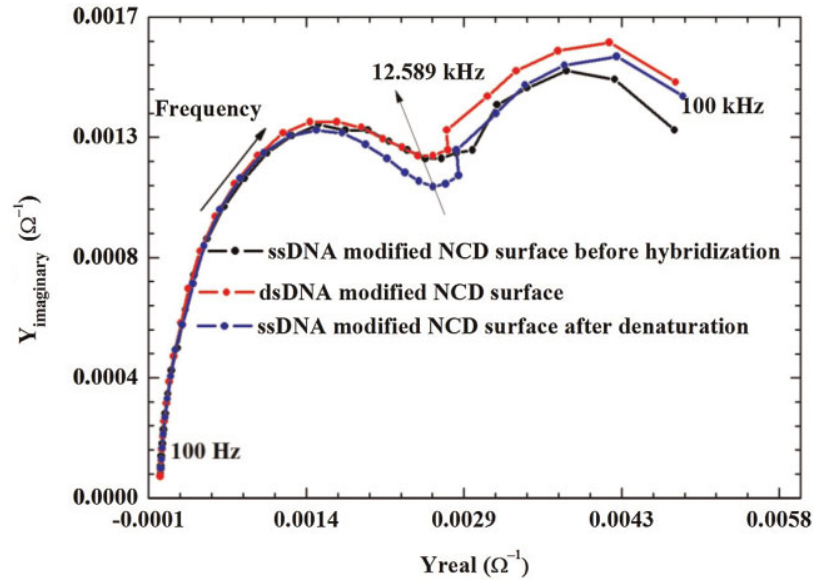

Figure 1 Nyquist plots for NCD, modified with ssDNA, then hybridized with its target and after denaturation.

changes in the molecular layer by $\mathrm{NaOH}$ [20]. The admittance was drawn instead of the impedance in order to get a higher resolution spectrum.

The full frequency spectrum of the impedimetrical data $(100 \mathrm{~Hz}$ to $100 \mathrm{kHz})$ can be simulated with a 5-element circuit consisting of a resistor, representing the bulk solution inside the flow cell, in series with two complex resistors, representing the molecular layer and space-charge region, respectively. This circuit is shown in Fig. 2. In the low frequency part, $R_{2}$ and $R_{3}$ will dominate most of the impedimetric signal with only a minor contribution of the capacitive elements inside the circuit. In the mid-frequency range, the capacitive elements play a more prominent role leading to a more pronounced imaginary part of the Nyquist plot in these frequencies. At $1 \mathrm{MHz}$, the impedance is dominated by the solution resistance $R_{1}$ [20].

3.2 Real-time monitoring of denaturation Hybridization induced a significant change in the impedance of the interface in the frequency range between $\sim 10 \mathrm{kHz}$ and $1 \mathrm{MHz}$ [20]. Therefore, the data was monitored at $12.589 \mathrm{kHz}$, ensuring a high effect size and a high signal-tonoise ratio and is not conflicting with the frequency of the power net (always a multiple of $50 \mathrm{~Hz}$ ). Figure 3 shows the

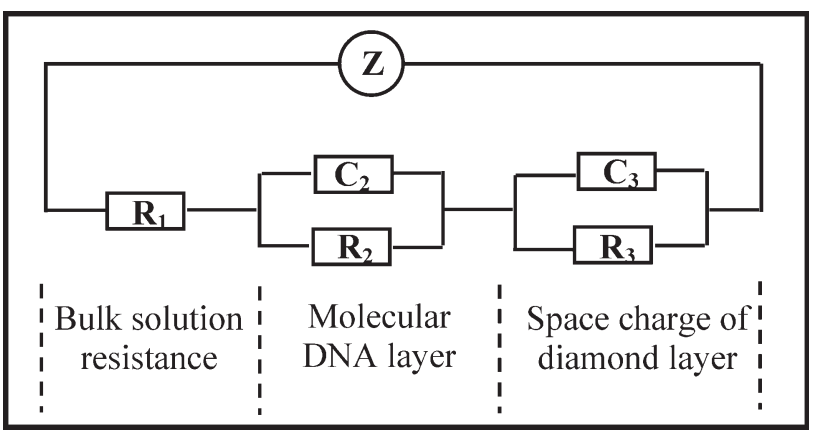

Figure 2 Circuit model used to analyse Nyquist plots.

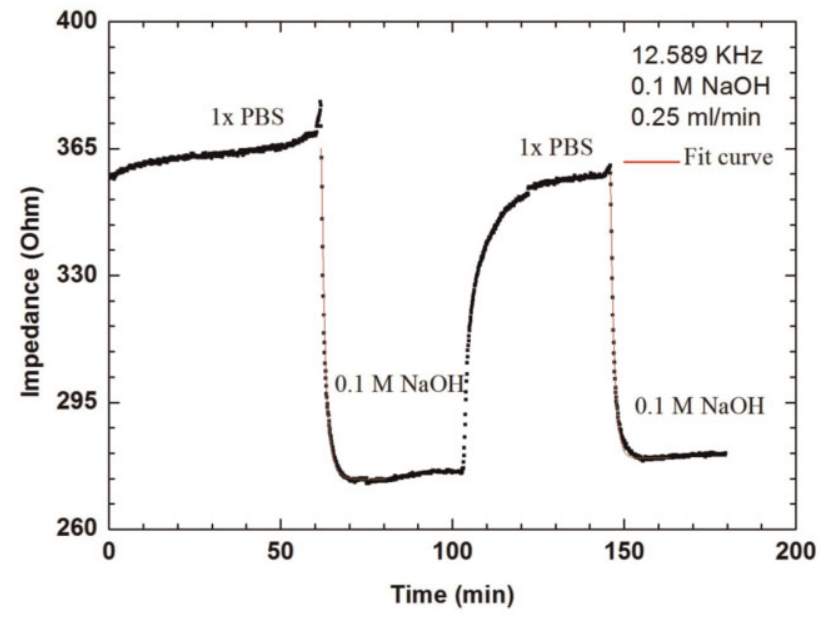

Figure 3 Real-time denaturation of dsDNA at $0.25 \mathrm{~mL} \mathrm{~min}^{-1}$ medium exchange flow rate and using $0.1 \mathrm{M} \mathrm{NaOH}$. The red curves indicate the exponential fits. Results are monitored at $12.589 \mathrm{kHz}$.

real-time denaturation of dsDNA immobilized onto borondoped NCD. First, $1 \times$ PBS was administered into the flow cell. After stabilization of the impedance, $0.1 \mathrm{M} \mathrm{NaOH}$ was injected into the cell, causing the dsDNA to denature. As a result the impedance started to decrease exponentially due to the denaturation effect and due to the fact that $0.1 \mathrm{M} \mathrm{NaOH}$ is more conductive than PBS [19]. However, a small overshoot was encountered as a result of the perturbation of the fluid in the cell caused by pumping medium into the flow cell.

After stabilization of the signal, $3 \mathrm{~mL}$ of PBS solution was pumped at a speed of $0.25 \mathrm{~mL} \mathrm{~min}^{-1}$ into the cell replacing any $\mathrm{NaOH}$ present in the cell, causing the impedance to increase again to a lower level than the initial PBS level. To determine the time constant of medium exchange, $\mathrm{NaOH}$ is administered a second time, causing a second decrease in impedance solely due to exchanging PBS with $\mathrm{NaOH}$. The time constants of denaturation $\left(\tau_{1}\right)$, and medium exchange $\left(\tau_{2}\right)$ were mathematically calculated using the following fit functions $[6,14,21]$ :

Fit function 1:

$$
Z(t)=Z(t=\infty)+A_{1} \cdot \exp \left\{-\frac{t}{\tau_{1}}\right\}+A_{2} \cdot \exp \left\{-\frac{t}{\tau_{2}}\right\},
$$

Fit function 2:

$$
Z(t)=Z(t=\infty)+A_{2} \cdot \exp \left\{-\frac{t-t_{2}}{\tau_{2}}\right\} .
$$

The double-exponential Fit function 1 for superimposed, independent decay processes is known e.g. from the decomposition of biomass (tomato leaves) and the mass loss of tomato DNA as a function of time [21] and the protein adsorption to solution-gate field-effect transistors [6]. The parameter $A_{1}$ represents the denaturation-related decay amplitude and $\tau_{1}$ the associated time constant; the amplitude $A_{2}$ refers to the impedance drop by the medium exchange and 


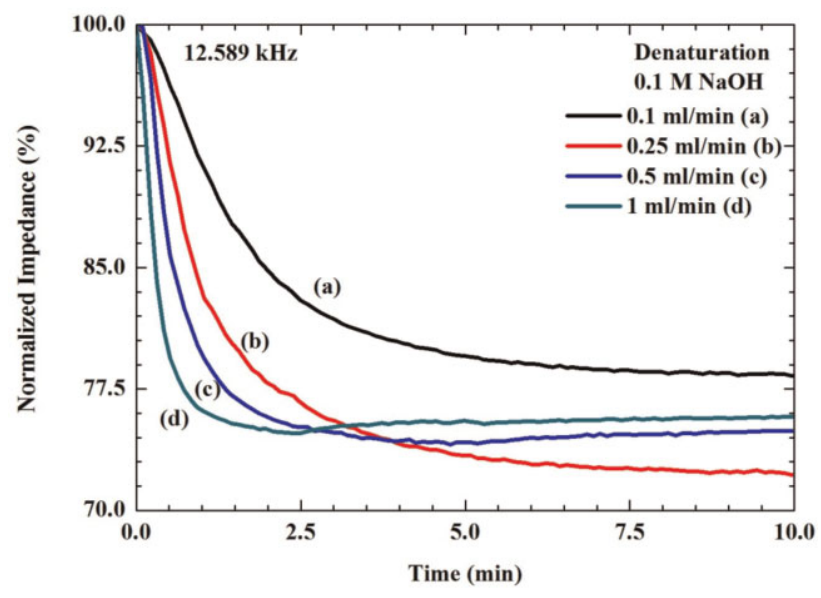

Figure 4 Normalized exponential decay at different mediumexchange flow rates using $0.1 \mathrm{M} \mathrm{NaOH}$ as a denaturing agent.

$\tau_{2}$ is the corresponding time constant. The Fit function 2 describes solely the influence of the medium exchange from $1 \times$ PBS to $0.1 \mathrm{M} \mathrm{NaOH}$ after the denaturation has taken place and is therefore representative for the medium exchange as such. The values for $\tau_{1}$ and $\tau_{2}$, calculated in this way were $2.3 \pm 0.2 \mathrm{~min}$ (95\% confidence limit) and $1.1 \pm 0.01 \mathrm{~min}$, respectively. These values correlate well with values described by van Grinsven et al. [14]. To determine the effect of slow and fast medium exchange on the denaturation time constant of dsDNA, measurements were performed at four different flow rates $(0.1,0.25,0.5$ and $1 \mathrm{~mL} \min ^{-1}$ ). The data were analysed as described above.

Figure 4 shows the normalized impedance decay at these four flow rates. It can be observed that the increase in flow rate caused the dsDNA to denature faster. The time constant for denaturation $\tau_{1}$ decreased from $3.5 \pm 0.01$ to $2.3 \pm 0.2$,

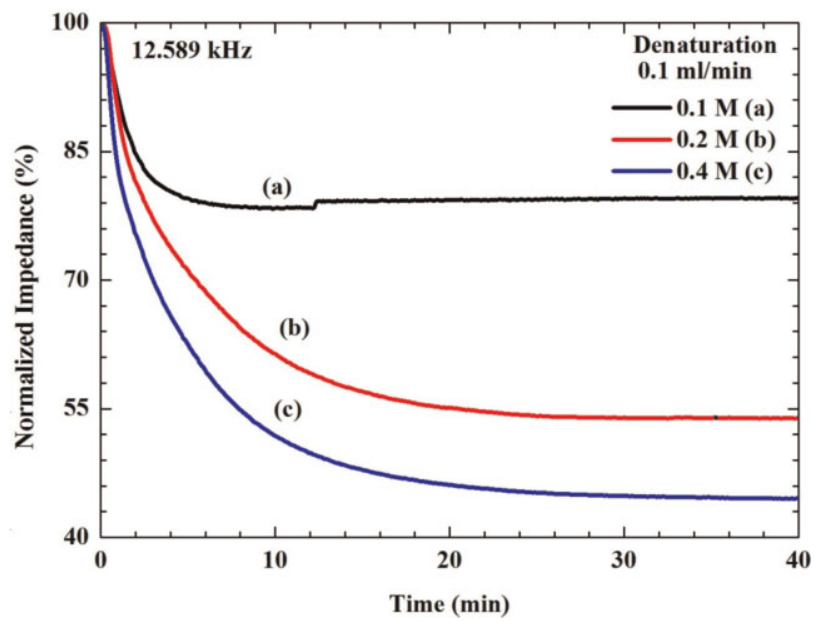

Figure 5 Normalized exponential decay at a fixed flow rate of $0.1 \mathrm{~mL} \mathrm{~min}^{-1}$, using different molarities of $\mathrm{NaOH}(0.1,0.2$ and $0.4 \mathrm{M})$.

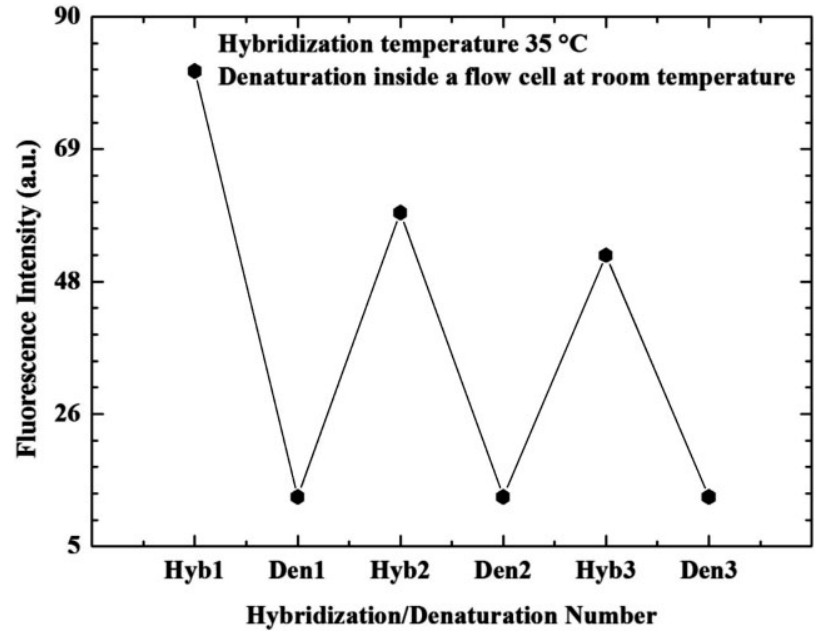

Figure 6 Fluorescence intensity graph after successive hybridization and denaturation steps.

$0.8 \pm 0.2$ and $0.6 \pm 0.1 \mathrm{~min}$, respectively. Next, the change in denaturation time constant as a function of $\mathrm{NaOH}$ concentration change was analysed at a constant flow rate of $0.1 \mathrm{~mL} \mathrm{~min}^{-1}$ by using three different $\mathrm{NaOH}$ concentrations $(0.1,0.2$ and $0.4 \mathrm{M})$ as shown in Fig. 5. The increase in $\mathrm{NaOH}$ concentration caused the dsDNA to denature faster. It was calculated that the time constant for denaturation $\tau_{1}$ decreased from $3.5 \pm 0.01$ to $1.8 \pm 0.3$ and $0.9 \pm 0.05 \mathrm{~min}$, respectively, at increasing concentrations of $\mathrm{NaOH}$. Fluorescence images were taken after every hybridization and denaturation step to support tee experiments. The results are summarized in Fig. 6. The average fluorescence intensity after 3 hybridization cycles is 63 arbitrary units (a.u.). The average fluorescent intensity after denaturation is 14 a.u., proving complete denaturation of the dsDNA.

In addition, denaturation was also performed using $0.05 \mathrm{M} \mathrm{NaOH}$ at a constant flow rate of $1 \mathrm{~mL} \mathrm{~min}^{-1}$. The results are shown in Fig. 7. It could be observed that the impedance showed an exponential growth rather than a decay when denaturing the DNA using $0.05 \mathrm{M} \mathrm{NaOH}$. This can be explained by the fact that $0.05 \mathrm{M} \mathrm{NaOH}$ holds a lower salt concentration than $1 \times$ PBS, resulting in a lower conductivity. These results were confirmed by conductivity measurements summarized in Table 1. Time constants were calculated in a similar manner as described above. This behaviour was analysed at the four flow rates described earlier. The denaturation at $0.5 \mathrm{~mL} \mathrm{~min}^{-1}$ speed showed a similar behaviour. The respective time constants for denaturation $\tau_{1}$ at 1 and $0.5 \mathrm{~mL} \mathrm{~min}^{-1}$ were $1.2 \pm 0.1$ and $1.7 \pm 0.3 \mathrm{~min}$, respectively. Decreasing the flow rate to 0.25 and $0.1 \mathrm{~mL} \mathrm{~min}^{-1}$ resulted in a drift in impedance at the first and second $\mathrm{NaOH}$ plateau.

To understand this behaviour in more detail, confocal images were taken at these plateaus as well as at the first PBS plateau (indicated as a, b and c in Fig. 7) when measuring at these low flow rates. The resulting fluorescence profiles were 


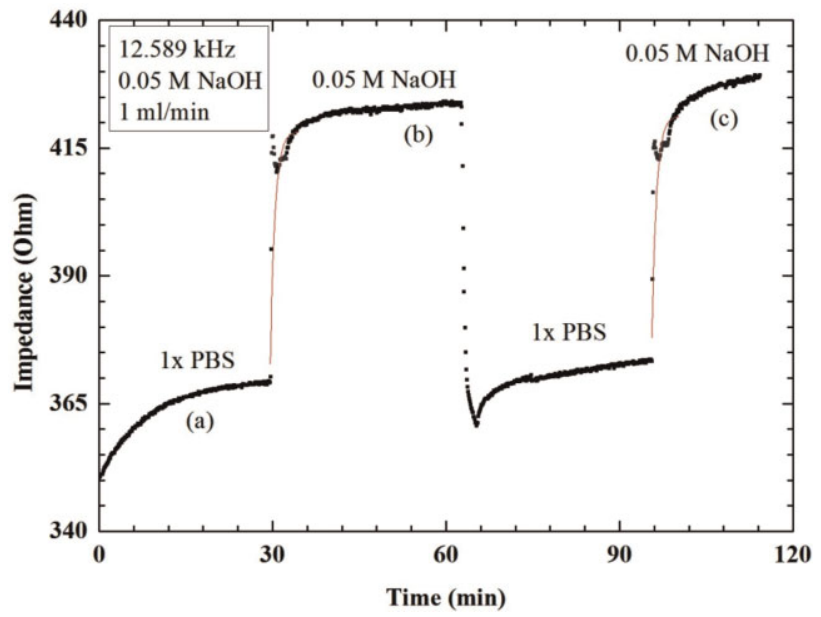

Figure 7 Real-time denaturation of dsDNA at $1 \mathrm{~mL} \mathrm{~min}^{-1}$ medium exchange flow rate and using $0.05 \mathrm{M} \mathrm{NaOH}$. Results are monitored at $12.589 \mathrm{kHz}$.

Table 1 Conductivity measurements performed on the solutions used during electrochemical monitoring of denaturation.

\begin{tabular}{ll}
\hline solution & $\begin{array}{l}\text { conductivity } \\
\left(\mathrm{mS} \mathrm{cm}^{-1}\right)\end{array}$ \\
\hline $1 \times \mathrm{PBS}$ & 13.3 \\
$0.05 \mathrm{M} \mathrm{NaOH}$ & 11.2 \\
$0.1 \mathrm{M} \mathrm{NaOH}$ & 22.3 \\
$0.2 \mathrm{M} \mathrm{NaOH}$ & 42.1 \\
$0.4 \mathrm{M} \mathrm{NaOH}$ & 79.2 \\
\hline
\end{tabular}

plotted in 3D graphs using the 'interactive 3D surface plot' plugin in ImageJ as shown in Fig. 8. Hybridization of target DNA was achieved as can be concluded from Fig. 8a. After the first addition of $\mathrm{NaOH}$, not all DNA was denatured as proven by the image in Fig. 8b, showing that part of the DNA is still present on the sample. To give a more complete overview of the sample coverage, a bigger area was scanned. This provides an explanation for the continuous drift in impedance at these low flow rates. After a second addition of $\mathrm{NaOH}$ to the flow cell, the DNA was denatured more completely, as can be obtained from Fig. 8c. The little remaining DNA on the surface explains why a small drift is still observed after the second addition of $0.05 \mathrm{M} \mathrm{NaOH}$ at these low flow rates. The interactive 3D surface plot settings were for Fig. 8a: grid size 128, smoothing 3.0, max 32\% and $\min 27 \%$ and for the Fig. $8 \mathrm{~b}$ and c: grid size 128 , smoothing 3.0, $\max 40 \%$ and $\min 8 \%$.

4 Discussion This paper provides an overview of the effect of varying flow rates and $\mathrm{NaOH}$ concentration on the denaturation time constant $\tau_{1}$ and the medium-exchange constant $\tau_{2}$. Measurements were performed at four different flow rates and four different $\mathrm{NaOH}$ concentrations. Table 2

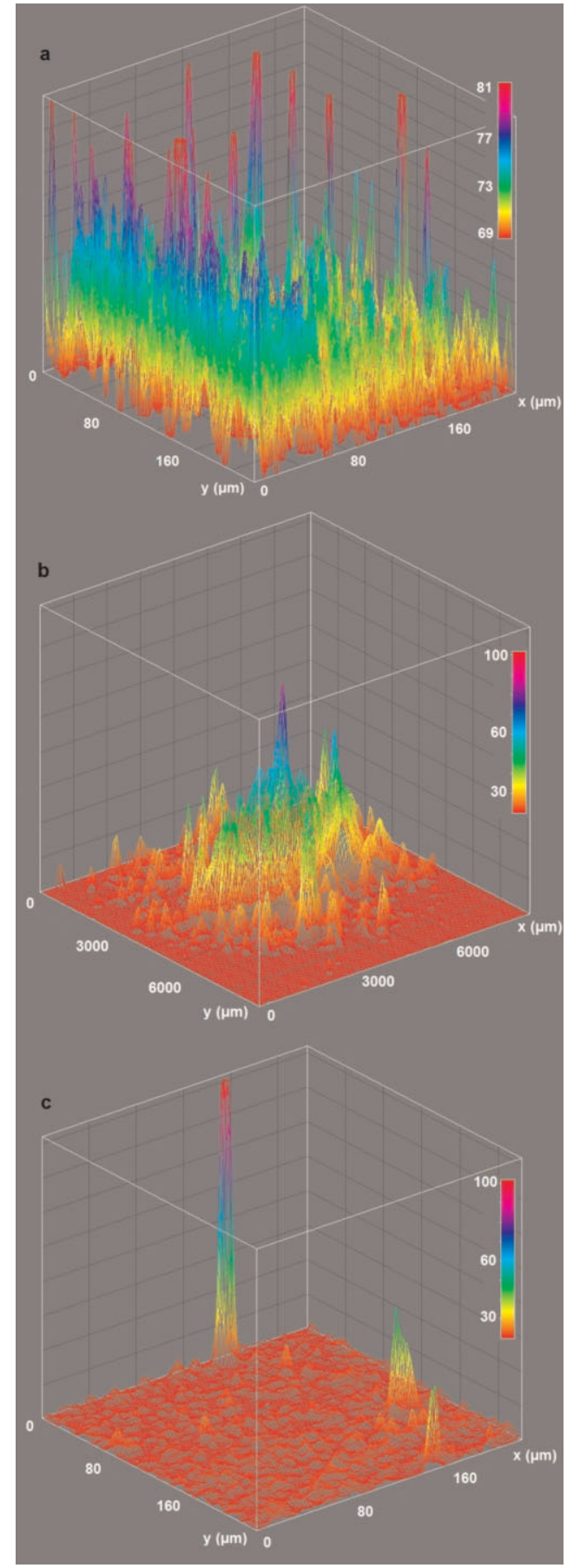

Figure 8 Fluorescence 3D graphs after $0.05 \mathrm{M} \mathrm{NaOH}$ introduction into the flow cell. Panels a,b and c correspond with points $\mathrm{a}, \mathrm{b}$ and $\mathrm{c}$ in Fig. 7. (a) Surface plot of NCD modified with dsDNA $\left(225 \times 225 \mu \mathrm{m}^{2}\right)$. (b) Surface plot of the same sample after the first addition of $0.05 \mathrm{M}$ $\mathrm{NaOH}$ at a flow rate of $0.1 \mathrm{~mL} \mathrm{~min}^{-1}\left(9000 \times 9000 \mu \mathrm{m}^{2}\right)$. (c) Surface plot of the same sample after a second addition of $\mathrm{NaOH}$ of the same molarity at the same flow rate $\left(225 \times 225 \mu \mathrm{m}^{2}\right)$.

summarizes the denaturation and medium exchange time constants for $0.05,0.1,0.2$ and $0.4 \mathrm{M} \mathrm{NaOH}$ as a function of flow rate. It can be concluded from these results that $\tau_{1}$ decreases with increasing flow rate for all molarities of 
Table 2 Denaturation and medium-exchange time constants $\left(\tau_{1}\right.$ and $\left.\tau_{2}\right)$ at differential flow rates and different $\mathrm{NaOH}$ concentrations.

\begin{tabular}{|c|c|c|c|c|c|}
\hline & $\begin{array}{l}\text { medium-exchange } \\
\text { flow rate }\left(\mathrm{mL} \mathrm{min}^{-1}\right)\end{array}$ & $\tau_{1}(\min )$ & $\begin{array}{l}\text { denaturation } \\
R^{2}\end{array}$ & $\tau_{2}(\min )$ & $\begin{array}{l}\text { medium } \\
\text { exchange } R^{2}\end{array}$ \\
\hline \multirow[t]{4}{*}{$0.05 \mathrm{M} \mathrm{NaOH}$} & 0.10 & / & / & l & / \\
\hline & 0.25 & I & I & l & l \\
\hline & 0.50 & $1.7 \pm 0.3$ & 0.968 & $1.2 \pm 0.1$ & 0.946 \\
\hline & 1.00 & $1.2 \pm 0.1$ & 0.948 & $0.8 \pm 0.1$ & 0.977 \\
\hline \multirow[t]{4}{*}{$0.1 \mathrm{M} \mathrm{NaOH}$} & 0.10 & $3.5 \pm 0.01$ & 0.996 & $1.6 \pm 0.02$ & 0.996 \\
\hline & 0.25 & $2.3 \pm 0.2$ & 0.993 & $1.1 \pm 0.01$ & 0.993 \\
\hline & 0.50 & $0.8 \pm 0.2$ & 0.986 & $0.7 \pm 0.02$ & 0.993 \\
\hline & 1.00 & $0.6 \pm 0.1$ & 0.989 & $0.3 \pm 0.01$ & 0.995 \\
\hline \multirow[t]{4}{*}{$0.2 \mathrm{M} \mathrm{NaOH}$} & 0.10 & $1.8 \pm 0.3$ & 0.979 & $3.9 \pm 0.1$ & 0.962 \\
\hline & 0.25 & $1.3 \pm 0.3$ & 0.988 & $2.4 \pm 0.1$ & 0.980 \\
\hline & 0.50 & $0.6 \pm 0.2$ & 0.974 & $1.1 \pm 0.1$ & 0.971 \\
\hline & 1.00 & $0.3 \pm 0.1$ & 0.990 & $0.6 \pm 0.02$ & 0.990 \\
\hline \multirow[t]{4}{*}{$0.4 \mathrm{M} \mathrm{NaOH}$} & 0.10 & $0.9 \pm 0.1$ & 0.932 & $2.5 \pm 0.1$ & 0.912 \\
\hline & 0.25 & $0.5 \pm 0.1$ & 0.932 & $1.6 \pm 0.04$ & 0.944 \\
\hline & 0.50 & $0.3 \pm 0.1$ & 0.967 & $1.5 \pm 0.03$ & 0.921 \\
\hline & 1.00 & $0.2 \pm 0.04$ & 0.975 & $0.9 \pm 0.02$ & 0.907 \\
\hline
\end{tabular}

$\mathrm{NaOH}$. Furthermore, $\tau_{1}$ decreases at increasing concentration of $\mathrm{NaOH}$ at constant flow rate. In addition the denaturation time values at $0.1 \mathrm{M} \mathrm{NaOH}$ and $0.25 \mathrm{~mL} \mathrm{~min}^{-1}$ flow rate correlate well with denaturation time constant values reported by van Grinsven et al. [14]. However, when using $0.05 \mathrm{M} \mathrm{NaOH}$ a flow rate of at least of $0.5 \mathrm{~mL} \mathrm{~min}^{-1}$ is required to fully denature the DNA during the first addition of $\mathrm{NaOH}$. This can be attributed to the fact that there is less shear force in the cell at low flow rates, and as a result only chemical denaturation is taking place with no frictional force to enhance the denaturation. At high concentrations of $\mathrm{NaOH}$ the DNA can be denatured by chemical denaturation alone, whereas at $0.05 \mathrm{M} \mathrm{NaOH}$ the concentration is too low to fully denature the DNA and thus requiring additional frictional shear force.

5 Conclusions The results provided in this paper prove that the denaturation times provided by van Grinsven et al. [14] can be decreased by increasing the flow rate or the concentration of $\mathrm{NaOH}$. Measurements performed using low concentrations of $\mathrm{NaOH}$ show that high flow rates are necessary to denature the DNA. The mechanical force exerted by the fluid motion contributes to the denaturation of the dsDNA and the removal of the denatured strands. Therefore, the $\mathrm{NaOH}$ concentration should be at least $0.1 \mathrm{M}$ to ensure full denaturation of the dsDNA at flow rates below $0.5 \mathrm{~mL} \mathrm{~min}^{-1}$. Optimal conditions for industrial applications, requiring high throughput can be found in the high molarity and high flow rate range were denaturation occurs faster. However, if the application requires more detail, lower flow rates at a $\mathrm{NaOH}$ concentration of $0.1 \mathrm{M}$ should be used.

Acknowledgements Financial support by the Life-Science Initiative of the Province of Limburg and the Research Foundation Flanders FWO (Project G.0829.09: 'Synthetic diamond films as platform material for novel DNA sensors with electronic detection principles') is greatly appreciated.

\section{References}

[1] S. Wenmackers, V. Vermeeren, M. vande Ven, M. Ameloot, N. Bijnens, K. Haenen, L. Michiels, and P. Wagner, Phys. Status Solidi A 206, 391-408 (2009).

[2] V. Vermeeren, S. Wenmackers, M. Daenen, K. Haenen, O. A. Williams, M. Ameloot, M. vandeVen, P. Wagner, and L. Michiels, Langmuir 24, 9125-9134 (2008).

[3] P. Christiaens, V. Vermeeren, S. Wenmackers, M. Daenen, K. Haenen, M. Nesládek, M. vandeVen, M. Ameloot, L. Michiels, and P. Wagner, Biosens. Bioelectron. 22, 170-177 (2006).

[4] W. Yang, J. E. Butler, W. Cai, J. Carlisle, D. Gruen, T. Knickerbocker, J. N. Russell, Jr., L. M. Smith, and R. J. Hamers, Nature Mater. 1, 253-257 (2002).

[5] O. A. Williams and M. Nesládek, Phys. Status Solidi A 13, 3375-3386 (2006).

[6] M. Krátká, A. Kromka, E. Ukraintsev, M. Ledinský, A. Brož, M. Kalbacova, and B. Rezek, Sens. Actuators B 166-167, 239-245 (2012).

[7] S. Ingebrandt, Y. Hana, F. Nakamura, A. Poghossian, M. J. Schöning, and A. Offenhäusser, Biosens. Bioelectron. 22, 2834-2840 (2007).

[8] A. Poghossian, M. H. Abouzar, F. Amberger, D. Mayer, Y. Han, S. Ingebrandt, A. Offenhäusser, and M. J. Schöning, Biosens. Bioelectron. 22, 2100-2107 (2007).

[9] M. Yu. Vagin, A. A. Karyakin, and T. Hianik, Bioelectrochemistry 56, 91-93 (2002).

[10] A. Poghossian, M. H. Abouzar, M. Sakkari, T. Kassab, Y. Han, S. Ingebrandt, A. Offenhäusser, and M. J. Schöning, Sens. Actuators B 118, 163-170 (2006).

[11] L. Grieten, S. D. Janssens, A. Ethirajan, N. Vanden Bon, M. Ameloot, L. Michiels, K. Haenen, and P. Wagner, Phys. Status Solidi A 208, 2093-2098 (2011).

[12] W. S. Yeap, Y. Y. Tan, and K. P. Loh, Anal. Chem. 80, 46594665 (2008). 
[13] X. Wang, Y. Ishii, A. R. Ruslinda, M. Hasegawa, and H. Kawarada, ACS Appl. Mater. Interfaces 4, 3526-3534 (2012).

[14] B. van Grinsven, N. Vanden Bon, L. Grieten, M. Murib, S. D. Janssens, K. Haenen, E. Schneider, S. Ingebrandt, M. J. Schöning, V. Vermeeren, M. Ameloot, L. Michiels, R. Thoelen, W. De Ceuninck, and P. Wagner, Lab Chip 11, 1656-1663 (2011).

[15] B. van Grinsven, N. Vanden Bon, H. Strauven, L. Grieten, M. Murib, K. L. Jimenez Monroy, S. D. Janssens, K. Haenen, M. J. Schöning, V. Vermeeren, M. Ameloot, L. Michiels, R. Thoelen, W. De Ceuninck, and P. Wagner, ACS Nano 6, 2712-2721 (2012).

[16] O. A. Williams, M. Nesládek, M. Daenen, S. Michaelson, A. Hoffman, E. Osawa, K. Haenen, and R. B. Jackman, Diam. Relat. Mater. 17, 1080-1088 (2008).
[17] V. Mortet, J. D’Haen, J. Potmesil, R. Kravets, I. Drbohlav, V. Vorlicek, J. Rosa, and M. Vanecek, Diam. Relat. Mater. 14, 393-397 (2005).

[18] S. Wenmackers, S. D. Pop, K. Roodenko, V. Vermeeren, O. A. Williams, M. Daenen, O. Douhéret, J. D’Haen, A. Hardy, M. K. Van Bael, K. Hinrichs, C. Cobet, M. vandeVen, M. Ameloot, K. Haenen, L. Michiels, N. Esser, and P. Wagner, Langmuir 24, 7269-7277 (2008).

[19] B. van Grinsven, T. Vandenryt, S. Duchateau, A. Gaulke, L. Grieten, R. Thoelen, S. Ingebrandt, W. De Ceuninck, and P. Wagner, Phys. Status Solidi A 207, 919-923 (2010).

[20] W. Yang, J. E. Butler, J. N. Russell, Jr., and R. Hamers, Langmuir 20, 6778-6787 (2004).

[21] J. Poté, P. Rossé, W. Roselli, W. T. Van, and W. Wildi, Chemosphere 61, 677-684 (2005). 